\title{
La política de drogas en lberoamérica
}

\author{
Robles Orozco, G.
}

Delegado de Gobierno para el Plan Nacional sobre Drogas

Enviar correspondencia a:

Gonzalo Robles. Plan Nacional sobre Drogas. Recoletos, 22. 28001 Madrid

\section{RESUMEN:}

Existe la necesidad de colaborar entre países para abordar la complejidad de la problemática sobre drogas tanto en lo que se refiere a la prevención de la demanda como de la oferta, así como en el tratamiento y la reinserción. Dentro de esta cooperación entre países iberoamericanos ocupa un lugar privilegiado por España por razones culturales e históricas.

Esta colaboración, que se ha considerado una prioridad desde la Delegación del Gobierno para el Plan Nacional sobre Drogas, se ha establecido a los más diversos niveles: apoyo en la creación de la Red Iberoamericana de Organizaciones no Gubernamentales que trabajan en Drogodependencias (RIOD) que agrupa a las principales ONGs de España e Iberoamérica; apoyo en la formación a través de un master on-line en drogodependencias que va a poner en marcha la Red Iberoamericana de Universidades con postgrado en Drogodependencias o becas de postgrado en drogodependencias financiadas por la $\mathrm{AECl}$; fortalecimiento de las Comisiones Nacionales de Drogas de estos países y la constitución de los respectivos Observatorios Nacionales de Drogas; control de la oferta de drogas mediante la cooperación judicial y la lucha contra el blanqueo de capitales, etc.

Palabras clave: cooperación internacional, España, Latinoamérica, redes, drogas,

\begin{abstract}
Co-operation between countries is very necessary to tackle the complexity of the drug problem both in relation to prevention of the demand and to the supply, in addition to treatment and reinsertion. Spain occupies an important position in this cooperation between the South American countries for cultural and historical reasons.

This co-operation, considered a priority by the Government Delegation for the National Drug Plan, has been established at a variety of levels - support for the creation of the South American Network of NGOs working with Drug Addicts (RIOD), which encompasses the principal NGOs in Spain and South America; support for training through an on-line Masters in Drug Addiction which is about to be put into operation by the South American Universities Network with a postgraduate course in drug addictions or postgraduate scholarships in drug addictions, financed by the $\mathrm{AECl}$; strengthening the National Drug Commissions in these countries and the establishment of the respective National Drug Observatories; control of the drug supply through judicial co-operation and the battle against money laundering, etc.
\end{abstract}

Key words: international co-operation, Spain, Latin America, networks, drugs
| carácter transnacional del fenómeno de las drogas hace de la cooperación internacional un instrumento esencial para luchar contra este problema, tal como reconoce la Estrategia Nacional sobre Drogas 2000-2008, aprobada por el Consejo de Ministros el 17 de diciembre de 1997.

Hoy día se reconoce la imposibilidad de acabar con esta compleja realidad de forma individual, de ahí la importancia de la cooperación internacional. Toda política de drogas planteada exclusivamente desde una óptica nacional o local está abocada al fracaso en el corto plazo.

Dos son los principios que deben presidir la cooperación internacional, por un lado, el principio de res- ponsabilidad compartida de todos los Estados frente a las drogas, y por otro, el principio de globalidad, en el sentido de realizar un enfoque multidisciplinar que incluya todos los ámbitos.

Si bien España concede una especial importancia a la cooperación en general, la cooperación con los países de lberoamérica ocupa un lugar muy destacado, lo cual resulta comprensible, no sólo por razones de índole histórica, política y cultural, sino también por las implicaciones que el narcotráfico tiene en una región donde se concentran los principales países productores de hoja de coca del mundo y que en los últimos años padece todas las nefastas consecuencias asociadas a este fenómeno. 
Si hasta hace poco tiempo estos países se caracterizaban, en unos casos, por su condición de productores de hoja de coca y, en otros, por su carácter de zonas de tránsito, en los últimos años se han detectado cultivos de amapola y, lo que es más preocupante, se ha constatado que los niveles de consumo, especialmente de cocaína pero también de heroína, están aumentando.

Toda estrategia destinada a la lucha contra el fenómeno de las drogas debe contemplar la cooperación internacional y debe enfrentarse a este problema desde una perspectiva global e integrada que incluya dos aspectos esenciales como son la reducción de la demanda de drogas y el control de su oferta.

Este planteamiento, plasmado en el Protocolo de Cooperación suscrito el 10 de mayo del presente año por los Ministros de Asuntos Exteriores y del Interior en representación de la Secretaría de Estado para la Cooperación Internacional y para Iberoamérica y la Delegación del Gobierno para el Plan Nacional sobre Drogas, preside las actividades de cooperación de España con Iberoamérica en la lucha contra el narcotráfico.

Por un lado, concede una especial atención al fortalecimiento institucional de los países de Centroamérica y de los países andinos y se consolida el trabajo hecho en colaboración con la Comisión Interamericana para el Control de Abuso de Drogas de la Organización de Estados Americanos; por otro, reconoce la importancia de abordar la lucha contra las drogas desde un planteamiento multidisciplinar que incluye la reducción de la demanda de drogas y el control de su oferta.

Las actividades desarrolladas en Centroamérica han posibilitado el fortalecimiento de las Comisiones Nacionales de Drogas de estos países y la constitución de los respectivos Observatorios Nacionales de Drogas. También han facilitado la elaboración de Planes Nacionales de Drogas y de una Estrategia Regional sobre Drogas.

Este planteamiento se va a reproducir en los países andinos, abogándose por llevar a cabo un programa de fortalecimiento institucional de sus Comisiones Nacionales de Drogas, habida cuenta de la necesidad de desarrollar las estructuras gubernamentales de estos países responsables de luchar contra el narcotráfico.

Además, España forma parte de las mesas de donantes constituidas por la comunidad internacional en Colombia y en Perú para ayudar a los Gobiernos de estos países en la lucha contra las drogas, apostando por desarrollar proyectos vinculados a la prevención de los consumos de drogas y el desarrollo alternativo.

Asimismo se trabaja en el ámbito de la reducción de la demanda de drogas a través de la consolidación de la Red Iberoamericana de Organizaciones no Gubernamentales que trabajan en Drogodependencias (RIOD) creada en 1998, y que agrupa a las principales ONGs de España e Iberoamérica que desarrollan bien programas de prevención del consumo de drogas, bien programas de tratamiento y rehabilitación de drogodependientes.

Igualmente, se favorece la formación de los profesionales que trabajan en este ámbito, quienes se podrán próximamente cursar un master on-line en drogodependencias que va a poner en marcha la Red Iberoamericana de Universidades con postgrado en Drogodependencias, o beneficiarse de una de las becas de postgrado en drogodependencias financiadas por la $\mathrm{AECl}$.

Por otro lado, se resalta la importancia del control de la oferta de drogas mediante la cooperación judicial y la lucha contra el blanqueo de capitales, para lo cual se han celebrado distintos seminarios de capacitación destinados, unos, a jueces y fiscales y, otros, a policías.

Se ha participado en la constitución de la Escuela Andina de Inteligencia Antidrogas, con sede en Lima, destinada a mejorar la formación de los miembros de la policía encargados de combatir el tráfico de drogas y se han organizado cursos de capacitación judicial en los distintos centros de formación de la $\mathrm{AECl}$.

Antes de concluir, debe recordarse que las relaciones entre España e Iberoamérica, en el marco de la UE en materia de drogas se desarrollan en el ámbito del Mecanismo de Coordinación y Cooperación entre la UE, América Latina y Caribe, marco general de cooperación en materia de drogas entre ambas regiones, que aborda desde una perspectiva coordinada, global e integral este fenómeno.

Este Mecanismo se ha traducido en la adopción de un Plan de Acción inspirado en los principios de responsabilidad compartida, enfoque integral, equilibrado y participativo, desarrollo sostenible y no injerencia en la soberanía de los Estados al objeto de fomentar y coordinar la cooperación orientada al fortalecimiento y al desarrollo de las políticas nacionales y regionales sobre drogas de la región.

Finalmente, para concluir cabe señalar que, aún cuando todavía el consumo indebido y el tráfico ilícito de drogas continúan siendo un problema de ámbito mundial, el desarrollo de una conciencia colectiva común y el fortalecimiento de los instrumentos de colaboración internacional posibilitarán la búsqueda de soluciones ante este fenómeno.

Debemos ser optimistas ante los resultados alcanzados, constatar la eficacia de la cooperación internacional en líneas de trabajo abiertas y perseverar en nuestros objetivos para ganar la batalla contra las drogas en beneficio de nuestra sociedad. 